\title{
Los errores Charrúa y Guenoa-Minuán
}

\author{
por Diego Bracco
}

\begin{abstract}
The main goal of this article is to outline important historiographic errors concerning the nomadic Indians that occupied the grasslands located east of the Paraná River, south of the beginning of the rainforest area and west of the basin of the "laguna de los Patos". These errors have hindered the understanding of important processes such as the consolidation and the following decline of the Jesuit missions and the process of colonial occupation. This article tries to show the error of overestimating the role of the Charrúa Indians. Furthermore, it is also intended to show evidence that historiography has misinterpreted the power and extension of the nation called Guenoa-Minuana.
\end{abstract}

Algunos problemas historiográficos referidos al espacio de llanuras situado al oriente del río Paraná, al sur del comienzo de la zona de bosque subtropical y al oeste de la cuenca de la laguna de los Patos derivan de la falta de estudios de larga duración. Otros problemas dependen del sesgo nacionalista de trabajos que abordan el pasado de un territorio que hoy ocupan varios Estados pero que fue una unidad durante centurias. Entre esos problemas cabe situar al inadecuado conocimiento de los grupos indígenas que habitaban el territorio, con evidentes consecuencias hacia la comprensión de fenómenos como la consolidación y disgregación de la sociedad jesuítico-guaraní del Uruguay y el proceso de ocupación colonial del territorio.

Este artículo se centrará en destacar el error derivado de sobredimensionar el papel de la "nación" charrúa. ${ }^{1}$ También procurará de-

1 Tal centro de atención no significa ignorar la importancia de otros grupos como los guaraníes, chanáes e incluso pampas que con frecuencia fueron "desnaturalizados" en territorio oriental del río Paraná. Tampoco implica desconocer que problemas relacionados con el deficiente conocimiento ha obligado a agrupar bajo la denominación "charrúa" a indígenas que - como los yaros y más aún los bohanes - tal vez no lo hayan sido. 
mostrar que tal extremo supuso un equívoco vinculado al desconocimiento de la importancia de la "nación" que los jesuitas llamaron guenoa y los españoles y portugueses minuana. ${ }^{2}$

El material disponible presenta numerosas limitaciones que conllevan diversas incongruencias. Las principales de ellas derivan de la calidad y cantidad de fuentes primarias disponibles, casi inexistentes para el interior del territorio hasta que se completó la difusión del ganado europeo. Además de los habituales relacionados con las características del observador, la documentación presenta numerosos sesgos vinculados a la estacionalidad de la navegación del estuario del Plata y el tránsito del medio rural. Las fuentes son muy contradictorias cuando se refieren a las sociedades indígenas y resultan especialmente escasas durante los períodos de paz. Hasta que la región cobró interés por la difusión de vacunos y equinos, los europeos se mantuvieron en los bordes del espacio de llanuras. Hasta la segunda mitad del siglo XVII, la mayor parte de la documentación fue producida en esos bordes, especialmente en las desembocaduras de los ríos Uruguay y Paraná, y parte del curso de este último. Cuando la información se tornó abundante, ya se habían producido enormes cambios derivados del impacto de las enfermedades de origen europeo y de migraciones de indígenas procurando escapar de la esclavitud. La historiografía hoy aceptada sobre el mundo indígena se valió de datos obtenidos en los sitios antes mencionados o en fuentes extemporáneas. ${ }^{3}$

No hay prácticamente nada durante el siglo XVI que pueda decirse a ciencia cierta sobre el interior del territorio. Además, en la actualidad

\footnotetext{
Siguiendo a la documentación, fueron utilizados conceptos como "nación" a los que las fuentes asignaron significados muy diversos y generalmente diferentes a los actuales.

2 Con mucha reiteración la documentación permite establecer que los términos "guenoa" y "minuán", así como muchas variantes similares, fueron usados para designar la misma "nación". Ocasionalmente, tal extremo fue señalado a texto expreso. Así, poco antes de mediados de siglo XVIII se indicó que a ese presente ocupaban "la tierra desde el Uruguay hasta el mar la nación de los guenoas, que los españoles de Santa Fe y Buenos Aires suelen llamar; corrompido el vocablo, Minuanes". Pedro Lozano, Historia de la Conquista del Paraguay, Río de la Plata y Tucumán, tomo I (Buenos Aires 1873), p. 26.

La exhaustiva mención de tales fuentes escapa a las posibilidades e incluso al propósito de este trabajo ya que ello supondría citar lo que las fuentes no señalan, dentro de una enorme masa documental. En similar sentido cabe destacar que se han omitido referencias a hechos y personajes conocidos y por tanto fácilmente accesibles al lector familiarizado con el período y región.
} 
los historiadores tienden a descartar apreciaciones tradicionales, como la que atribuyó la temprana muerte de Juan Díaz de Solís a los charrúas. Un papel anónimo de la década de 1570 lo atribuyó a guaraníes, suposición que hoy tiende a aceptarse en atención a lo que se sabe de su radio de acción y sus rituales de antropofagia. ${ }^{4}$

Un somero repaso de las principales fuentes de información disponibles para el siglo XVI no hace sino confirmar la falta de datos. A continuación de la expedición de Solís, las armadas de Magallanes y Loaysa aportaron escasa información etnográfica. En cambio, a partir del arribo y establecimiento de las huestes de Gaboto y García en el Plata, hubo una multiplicación de las fuentes que se refieren a los indígenas. Por entonces, los europeos empezaron a dejar constancia escrita sobre los charrúas. ${ }^{5}$ No obstante, es preciso señalar que la información recabada estaba decisivamente influida por los lugares de establecimiento y tránsito de esas expediciones. Un pleito que se siguió contra Gaboto en Sevilla contiene una referencia sobre indígenas situados al este que por oposición parecen ser distintos de los charrúas. El referido capitán fue acusado de abandonar un grupo de sus hombres, ignorando señales con humo hechas desde el cabo Santa María. Gaboto, que entonces estaba regresando a España, se negó a ir, diciendo que sus hombres ya debían haber sido muertos por los indios y un testigo replicó "que no podía ser, porque aquellos indios de aquella tierra donde ellos fueron eran sus amigos y que no era posible haberlos muerto". La afirmación es relevante porque fue efectuada en un contexto en que la armada de Gaboto se había visto obligada a abandonar el bajo Uruguay frente a la hostilidad indígena. ${ }^{6}$

A principios de la década de 1530 Pero Lope de Souza escribió un precioso diario que contiene sus observaciones sobre la ribera norte del estuario del Plata. Aunque el texto está lleno de datos etnográficos

4 Archivo General de Indias (en adelante AGI), Patronato, 28. Papel anónimo y sin fecha que hace referencia a fundaciones que debía estar realizando Ortíz de Zárate, lo cual permite suponer que fue escrito en la década de 1570.

5 Con marcada imprecisión geográfica, las primeras referencias a charrúas se encuentran en la Historia General y Natural de las Indias (1535) de Gonzalo Fernández de Oviedo y en la memoria de Diego García. Véase Eduardo F. Acosta y Lara, La Guerra de los Charrúas (Montevideo/Buenos Aires 1998), pp. 3-4.

6 Información hecha por los Oficiales de la Casa de Contratación de Sevilla, luego que llegó la armada de Gaboto. Testimonio de Junco, 28 de julio de 1530. Publicada en José Toribio Medina, El veneciano Sebastián Caboto al servicio de España y especialmente de su proyectado viaje a las Molucas por el estrecho de Magallanes, tomo II (Santiago de Chile 1897), p. 151, doc. CXLIII. 
de interés, hay grandes dificultades para identificar los grupos que describió. En cualquier caso, no hizo referencia directa a charrúas. ${ }^{7}$ Unos años más tarde, las circunstancias relacionadas con la expedición de Pedro de Mendoza, la primera fundación de Buenos Aires, el tránsito de los ríos Paraná y Paraguay, la fundación de Asunción del Paraguay, y el establecimiento efímero en el bajo Uruguay proporcionaron abundante información. No obstante, es preciso señalar una vez más que tal información se refiere a los sitios antes nombrados y no contiene datos que permitan aventurar hipótesis sobre la realidad del interior. Desde entonces, y por motivos bien conocidos relacionados con el aislamiento de Asunción de Paraguay, hubo una casi completa falta de producción documental. Tal circunstancia se revirtió en el marco del proceso cuya consecuencia más notable fueron las fundaciones de Santa Fe, Buenos Aires (por segunda vez) y Corrientes. También las circunstancias de la expedición de Ortíz de Zárate, que fue desbaratada en el bajo Uruguay, contribuyeron a un notable aumento de las fuentes. ${ }^{8}$ No obstante, es indispensable volver a reiterar que los lugares de tránsito, establecimiento y derrota, y por tanto las observaciones de los europeos, fueron realizados en la misma porción del territorio. ${ }^{9}$

A principios de la década de 1580 actuaciones relacionadas con el naufragio de una de las naves de Francis Drake aportaron indicios que señalaron la presencia de indígenas distintos a los charrúas en el este del territorio. ${ }^{10}$ Luego de dos días de navegación por el estuario, los ingleses naufragaron y

\footnotetext{
7 Pero Lope de Souza, Diario da Navegaçâo (1530-1532), Francisco Adolfo Varnhaguen (ed.) (Lisboa 1839).

8 Martín del Barco Centenera, Argentina y Conquista del Río de la Plata, con otros acaecimientos de los reynos del Perú, Tucumán y estado del Brasil, (1602) (Buenos Aires 1912). Es generalmente aceptada la gran influencia que ese texto de propósito poético e histórico ejerció sobre la historiografía subsiguiente. Muchas de las características atribuidas a los charrúas parecen derivar de esa obra.

${ }^{9}$ La historiografía de los siglos XIX y XX atribuyó la muerte de Juan de Garay, que aconteció cerca de Santa Fe a principios de la década de 1580, a minuanes. No parecen existir pruebas que avalen tal hipótesis excepto alguna que por su debilidad no merece ser considerada tal, como cierta analogía entre el nombre del cacique al que se responsabilizó del hecho y el nombre minuán. Mañúa lo llamó Barco Centenera, quien denominó "mañuaes" a sus parciales. Barco, Argentina (nota 8), canto XXIV.

10 Adicionalmente, véase Hendrick Ottsen, "La expedición del buque holandés el Mundo de la Plata, 1598-1601": Revista de la Sociedad de Amigos de la Arqueología XV (Montevideo 1957), pp. 191-207. Resulta de interés destacar cierta similitud en la información sobre indígenas que en 1531 produjo Lope de Sousa, la producida en relación a Drake y la parca descripción del diario de Ottsen a fin de la centuria.
} 
"[...] otro día de mañana los cogieron los indios y defendiéndose, los indios mataron de dieciocho que eran, diez, y los ocho que quedaron los cautivaron y repartieron entre los principales indios que se hallaron en la refriega, y estando cautivos tiempo de más de un año se juntaron acaso unos con otros un día y determinaron de irse y venirse al pueblo y ciudad de Buenos Aires [...] el que se llama Richarte se aventuró y huyó de poder y casa del indio que lo tenía cautivo y se fue a otra nación de indios que se llaman charrúas los cuales indios al cabo de algunos días, vinieron a donde estaban el capitán Joan Drac [John Drake, sobrino de Francis] y le dieron noticia de cómo habían llegado en salvamento el dicho Richarte su compañero, y que estaba bueno en su tierra de ellos. Y aguardando oportunidad, la cual halló por tener guerra la nación en donde estaba cautivo con otros de la tierra adentro, y así se [...] fueron a la parte donde estaba el dicho Richarte [cautivo de los charrúas, de donde huyeron atravesando] el Río, que por aquella parte tiene siete leguas". ${ }^{11}$

Repetidamente, la documentación señala la cercanía e interacción de los charrúas con los establecimientos españoles. Así, por ejemplo, hacia fines del siglo XVI, las autoridades discutían la licitud de sus operaciones de captura de "piezas" para proveer a los españoles de Buenos Aires ${ }^{12}$ y Santa Fe. ${ }^{13}$

Por entonces, se produjo uno de los textos que más ha influido en la historiografía posterior, sin perjuicio de las muchas inexactitudes y generalizaciones que se le han señalado: La Argentina de Ruy Díaz de Guzmán. ${ }^{14}$ Nada evidencia que el autor dispusiera de información de la que carecían sus contemporáneos. ${ }^{15}$ No obstante, el mencionado autor se refirió a

“[...] más de 20.000 indios guaraníes, que los de aquella tierra llaman arachanes, no porque en la costumbre y lenguaje se diferencien de los demás de esta nación, sino porque traen el cabello revuelto y encrespado para arriba. Es gente dispuesta y corpulenta, y ordinariamente tienen guerra con los indios charrúas del Río de la Plata, y con otros de tierra adentro que llaman guayanaes, aunque este nombre dan a todos los que no son guaraníes [...] Corren toda esta isla [Maldonado] los indios charrúas de aquella costa, que es una gente muy dispuesta y crecida, la cual no se sustenta de otra cosa que de caza y pescado". ${ }^{16}$

11 Declaración de Alonso Pérez de Herrera por orden del Virrey Conde del Villar, Ciudad de los Reyes, 11 de febrero de 1587: Roberto Leviller, Gobernantes del Perú, tomo X (Madrid 1925), p. 424.

${ }^{12}$ Lino Gómez Canedo, "Un dictamen franciscano agustiniano sobre servicio personal y libertad de los indios del Río de la Plata - Lima, 1598": The Americas XI, 3 (Washington 1955).

13 Manuel M. Cervera, Poblaciones y Curatos (Santa Fe 1939).

14 Rui Díaz de Guzmán, La Argentina (Madrid 1986).

15 Véase la introducción de Enrique de Gandía: Ibidem, pp. 7-48.

16 Díaz, La Argentina (nota 14), pp. 65, 66 y 68. 
La influencia de Ruy Díaz de Guzmán fue muy grande. Así, a mediados del siglo XVIII, el ilustrado jesuita Lozano - sin citar, de acuerdo a lo que por entonces era corriente - se refirió a

"[...] más de 20.000 indios guaraníes que llamaban arachanes, no porque en las costumbres e idioma se diferenciasen de los demás de aquella nación, sino porque traían revuelto y encrespado el cabello: era gente bien dispuesta, corpulenta, y belicosa, ejercitando de continuo las armas con la nación de los charrúas que poblaban las costas del Río de la Plata y con los guayanás de tierra adentro [...] La [isla] de Maldonado fue habitada de los indios charrúas, que discurrían vagos por todo este país". 17

Es necesario destacar que la gran influencia de ambos autores en la historiografía posterior fue una de las variables relevantes en la tendencia a sobredimensionar la presencia charrúa.

Desde principios del siglo XVII hubo cierta ampliación del radio de acción de la sociedad colonial hacia el este. Ello alcanzó su máxima expresión con las entradas de Hernandarias en el litoral oriental del Uruguay y la ribera norte del Plata hasta Montevideo. Su rica correspondencia demuestra hasta qué grado el territorio era desconocido y en todo caso no arroja luz sobre lo que acontecía en el interior, más allá de la ribera del Uruguay y del Plata. En la década de 1620 se empezó a utilizar el río Uruguay como medio de comunicación entre Buenos Aires y el incipiente proyecto misionero que se desarrollaba cientos de kilómetros aguas arriba. Hasta entonces, a los charrúas que iban a Buenos Aires desde

“[...] sus asientos a rescatar con los españoles y a vender pescado las cuaresmas, nunca ningún gobernador los pudo sujetar ni obligar a que estuviesen en parte señalada [el gobernador Céspedes para poner en estado de defensa a Buenos Aires] se valió de las naciones de indios que están en reducciones e hizo lo mismo con los dichos charrúas, dándoles orden que trajesen sus mujeres e hijos, cosa nueva en estos en particular, y los alojó, que serían más de quinientas almas, en la playa de este Río, debajo del fuerte, dándoles todo lo necesario para su sustento [...] y teniéndolos sazonados después de haberles dado a entender muchas veces quien [era] Dios y su potestad, y el engaño en que vivían, dijeron que se reducirían en una isla que está en la boca del río Negro, treinta leguas de esta Ciudad, y cuatro arriba de la antigua población de San Salvador". ${ }^{18}$

\footnotetext{
${ }^{17}$ Lozano, Historia (nota 2), tomo I, pp. 18 y 26.

18 Información hecha en Buenos Aires a petición del gobernador Pedro Esteban Dávila acerca de los indios uruguay, tapes y viaza (copia), año 1834. Relación de Don Francisco de Céspedes, inserta en el expediente. Buenos Aires, 5 de febrero de 1626: AGI, Charcas, 28.
} 
Por entonces, desde Buenos Aires se percibía que al este y al norte habitaban "la tierra firme los indios llamados charrúas que son amigos y acuden a esta Ciudad a servir, pagándoselo". ${ }^{19}$ Y a principios de la década siguiente se informaba que "los charrúas que habitan de la otra banda de este gran Río, están quietos y pacíficos y acuden a servir a esta Ciudad". ${ }^{20}$

Los datos de buenas relaciones con los charrúas no pueden ser tomados como un absoluto porque la documentación abunda en ejemplos de división dentro de una misma "nación". En cualquier caso, en la década de 1640 un episodio de violencia marcó las relaciones entre españoles e "infieles". De un interrogatorio se desprende que el radio de acción de los charrúas se extendía incluso al oeste del Paraná, donde habían "muerto en el camino de Córdoba a Pedro Salvatierra y a otros", ${ }^{21}$ aunque el epicentro del conflicto se ubicó al sur de la actual provincia de Entre Ríos. ${ }^{22}$

Sin perjuicio del elevado grado de interacción con los indígenas circunvecinos, los españoles fueron descubriendo una compleja realidad étnica a medida que se produjo el proceso de ampliación del propio territorio. Tal realidad había estado oculta porque entre Buenos Aires, Santa Fe y Corrientes, y el vasto interior, se interponían los charrúas. Así, en la década de 1620, el gobernador Céspedes envió

"[...] a llamar con los mismos charrúas a los indios de la sierra de Maldonado, los cuales, en oyendo su nombre, el cacique mayor despachó otro menor, [...] [a quien el gobernador reclamó que] viniese con algunos indios recorriendo la costa por si algún navío diese en ella como ha sucedido otras veces. [...] [Así mismo requirió que se juntaran con los charrúas que por su orden estaban] vigiando la costa para dar aviso si viniesen velas". ${ }^{23}$

${ }^{19}$ Informe del piloto Baquio de Filicaya, con conformidad de varios de sus colegas, al gobernador Dávila, Buenos Aires, 30 de abril de 1626: Biblioteca Nacional de Buenos Aires, Colección de Copias (Viñas) del AGI (En adelante BNBA Col. Cop.), 4893. El informe está completado por el mencionado gobernador Dávila, sin fecha.

20 Carta del gobernador Céspedes al Rey, Buenos Aires, 30 de agosto de 1631: AGI, Charcas, 112.

${ }^{21}$ Interrogatorio inserto en los autos sobre encomienda del pueblo de San Pedro de Colastinés, cuyo encomendero era Antonio de Vera Mujica, Buenos Aires, 1662, pregunta no. 7: AGI, Escribanía de Cámara, 876 a.

22 Ibidem, pregunta no. 14.

${ }^{23}$ Informe del gobernador de Buenos Aires, Francisco de Céspedes. En información hecha en Buenos Aires a petición del gobernador Pedro Esteban Dávila, acerca de los indios uruguay, tapes y viaza, en la que se insertan varios pareceres e informes sobre dichos indios y países (copia), año 1634: AGI, Charcas, 28. 
La complejidad oculta tras los charrúas también tendió a quedar en evidencia a medida que se intensificó la utilización del río Uruguay como vía de comunicación entre Buenos Aires y los pueblos de misiones. Reiteradamente fue señalada la permanente interacción - y con creciente tendencia a la hostilidad - entre los charrúas y yapeyú. ${ }^{24}$ Además, a partir de la frecuentación del hasta entonces poco visitado salto del río Uruguay, empezaba a señalarse a texto expreso la presencia de nómadas que hasta entonces habían permanecido fuera del radio de acción colonial. Ello fue especialmente notable con relación a los guenoas-minuanes ${ }^{25}$ sin perjuicio de distintas variantes en la grafía. ${ }^{26}$ Desde entonces, y paralelamente a la ampliación de la penetración española que acompañó el proceso de difusión del ganado al este del río Uruguay, las referencias a esa "nación" se intensificaron. En el año 1655 el gobernador de Buenos Aires hizo un llamamiento a

"[...] todos los indios de las naciones Yaros, Mohanes, Güenoas y a las demás que estuvieren entre ellas, y en particular a don Pedro Guaytán, y Lumillán, y Cloyán, caciques y capitanes de dichas naciones [...] les ruega y pide [...] que como gente de buen ser, y que deben buscar su salvación en la otra vida [...] traten luego de reducirse y juntarse todos en forma de pueblo [en las reducciones del Uruguay, o] los trataré como a rebeldes". ${ }^{27}$

Informaciones fragmentarias refieren que a mediados de la década de 1650 se dio principio a una reducción de los indios guenoas. ${ }^{28}$ Dos

24 Yapeyú estaba emplazada en la ribera derecha del río Uruguay y fue la más austral de las reducciones jesuíticas. Por lo mismo, estuvo muy expuesta a la interacción con los "infieles" charrúas. Amplia documentación, especialmente las correspondientes cartas anuas, así lo evidencia.

25 Autos y diligencias del gobernador Laris sobre el oro, año 1647. Declaraciones de Felipe y Ventura. Santo Tomé, noviembre de 1647: AGI, Charcas 120.

${ }_{26}$ Guinoanes fue en este caso el nombre empleado. La documentación permite afirmar que ese, al igual que los nombres "guenoas", "güenoas", "guaynoas", "guinoas", "guinoanes", "guayantiranes", "binuanes" y "minuanes" fueron, entre otros, usados para identificar la misma "nación".

27 Carta del gobernador Baigorri, Buenos Aires, 21 de octubre de 1655: Cayetano Bruno, Historia de la Iglesia en la Argentina, vol. III (Buenos Aires 1968), p. 86.

28 Se intentó reducir a "guanoas y mocars y imbolomas [...] y estando ya dos Padres con ellos para hacer la reducción, pueblo e iglesia, se han inquietado con lo que les han dicho otros indios de que los querían los padres juntar para entregarlos por esclavos a los españoles, dejando a los Padres solos, y aún los quisieron matar, pero no es cosa nueva entre infieles estos recelos e inquietudes, y por eso se los ha de dejar". Respuesta del visitador general de la provincia del Paraguay, padre Andrés de Rada, al exhortatorio del oidor de la audiencia de Buenos Aires, Pedro de Rojas: Archivo General de la Nación Argentina (en adelante AGNA), IX-6-9-3. La licencia para proceder a esa reducción la dio el gobernador Baigorri el 21 de octubre de 1655. 
décadas más tarde los jesuitas alegaron carecer de padres suficientes para satisfacer el pedido de varios grupos que deseaban reducirse, entre los cuales estaban los guenoas. ${ }^{29}$ Para entonces se había completado el proceso de difusión de ganado. En ese contexto, las autoridades españolas afirmaron que los pueblos de misiones estaban amenazados porque "se había descubierto paso [...] hasta las doctrinas, por el mucho ganado que pasta en el paraje de Montevideo". ${ }^{30}$ En el marco de esos temores, los posibles invasores tenían

"[...] el paso seguro al Paraguay y Corrientes, por tierra firme, por las doctrinas que tienen los padres de la Compañía de Jesús en el Paraná y Uruguay, porque este dicho río se vadea en el verano por junto a una, que llaman la doctrina y pueblo de Yapeyú, por donde pasan los indios de nación guinoanes, que habitan y corren toda la campaña desde él, hasta Montevideo y Maldonado, que distan 250 leguas, a hurtar caballos a la jurisdicción de las Corrientes". ${ }^{31}$

A medida que la sociedad colonial multiplicó su conocimiento del interior, fue descrita reiterada y precisamente la amplitud de la presencia guenoa-minuana. Tal descripción fue concordante con la realizada por los jesuitas desde los pueblos de misiones. ${ }^{32}$

En circunstancias de las que aparentemente no se conservan testimonios, y cuya profundidad temporal es difícil evaluar, esa "nación" incorporó a su cultura cierto tipo de prácticas ganaderas. Al menos desde la década de 1670 los guenoas actuaban como pastores de ganado, tal vez procedente de los pueblos de misiones destruidos por los paulistas en la década de 1630 . No es posible determinar los caminos por los que devinieron pastores, aunque podría deberse a un proceso de aculturación relacionado con la dispersión subsiguiente a dicha

${ }^{29}$ Carta del gobernador de Paraguay al Rey, Asunción, 31 de marzo de 1678: AGI, Charcas, 150.

${ }^{30}$ Real Cédula de 7 de agosto de 1679 al gobernador de Buenos Aires: AGNA, Reales Cédulas, tomo 8, f. 75.

${ }^{31}$ Carta del gobernador Robles al Rey, Buenos Aires, 20 de junio de 1678: AGI, Charcas, 260.

${ }^{32}$ Francisco Jarque, Insignes Misioneros de la Compañía de Jesús (Pamplona 1687). En particular, los capítulos XXII a XXV proporcionan información de extraordinaria relevancia sobre los grupos indígenas de la región. Es notable en ese sentido la carta escrita por el padre Francisco García que visitó a los guenoas en sus tierras entre septiembre y octubre de 1683. No hay reediciones y se conservan escasos ejemplares del volumen editado hace más de tres siglos; no obstante, las características de este artículo impiden transcribir el texto. 
destrucción. En ese sentido, la difusión de productos como la yerba y el tabaco demuestra que la interacción era ya intensa en esa fecha. ${ }^{33} \mathrm{~A}$ partir de entonces, abundante documentación demuestra que reiteradamente se amparaban - a veces estacionalmente, a veces sólo sus mujeres y niños - en los pueblos de misiones, con obvias consecuencias hacia la aculturación para ellos y para los guaraníes que los recibían.

Las primeras descripciones minuciosas de esa "nación", y del territorio en que fue preponderante, datan de un momento en el cual ya se habían producido cambios enormes. Tal circunstancia aconseja completa prudencia a la hora de utilizar esas descripciones como referencia válida para la centuria anterior. Desde que hay documentación, las fuentes primarias señalan inequívocamente la preponderancia de la "nación" guenoa-minuana en el vasto espacio esquemáticamente comprendido entre el río Uruguay, los pueblos australes de la sociedad jesuítico-guaraní y el oeste de la cuenca de la Laguna de los Patos. Ello no permite afirmar tal preponderancia para el siglo XVI pero sin duda contribuye a refutar la suposición de una presencia charrúa en toda el área y, por tanto, pone en severo entredicho el mapa etnográfico generalmente aceptado. ${ }^{34}$

Las fuentes, que a partir del año 1680 se multiplicaron, continuaron evidenciando la preponderancia charrúa entre los ríos Paraná y Uruguay y en la ribera izquierda de este último. ${ }^{35}$ Entre los charrúas y los guenoas-minuanes había un estado de guerra permanente, con exterminio de prisioneros. Las guerras las hacían por "robarse unos a otros sus caballos y mujeres". ${ }^{36}$ Se señaló que los primeros operaban entre el Paraná y el Uruguay, y los segundos al oriente de este último. Se especificó que

33 Billete escrito por el Padre Leandro Salinas [...] de casi setenta años; de misionero de más de cuarenta [...] Superior dos veces, y rector del Colegio Máximo de Córdoba, fechado sin lugar, a 20 de mayo de 1715. En información sobre el derecho que tienen los indios guaraníes a las vaquerías del mar, julio de 1716: AGNA, Cía de Jesús, Legajo 3.

34 Interesante intento de revisión puede verse en Ítala Irene Basile Becker, El indio y la Colonización. Charrúas y Minuanes (Brasil 1984).

35 Las fuentes que hacen referencia al accionar charrúa en ese territorio son muy abundantes. Prueba documental puede encontrarse en Manuel D. Cervera, Historia de la Ciudad y Provincia de Santa Fe (Santa Fe 1907). También en Juan F. Sallaberry S.J., Los Charrúas y Santa Fe (Montevideo 1926).

36 Información ordenada en Santa Fe, a 22 de julio de 1689. Adjunta a carta del gobernador de Buenos Aires al Rey, Buenos Aires, 28 de abril de 1690: AGI, Charcas, 261. 
"[...] de la otra banda del río Paraná asisten varias naciones de indios que generalmente llaman charrúas, que son en número de más de dos mil familias, y que éstos tienen guerras con otras naciones de indios así mismo gentiles, que llaman guinoanes, de menos número que los charrúas, a quienes divide sus tierras la breve interposición del río Uruguay". ${ }^{37}$

Por entonces las autoridades españolas temían que - sin perjuicio de su rivalidad - tanto charrúas como guenoas cooperaran con los portugueses establecidos en Colonia del Sacramento. ${ }^{38}$ Además, el equilibrio de poder entre los nómadas estaba amenazado ya que los charrúas estaban "a la sazón muy recelosos de que [sus enemigos] los venciesen y destruyesen por haberse amistado con los portugueses, que con su fomento no dudaba los destruirían". 39

Cuando principiaba el siglo XVIII el temor a la expansión portuguesa potenció el conflicto de larga duración que mantenían charrúas y guenoas-minuanes. En ese contexto, un ejército de guaraníes misioneros, al que se había sumado un fuerte contingente de guenoas-minuanes, mató cientos de nómadas procedentes de entre los ríos Paraná y Uruguay en la denominada "batalla del Yi", en territorio oriental del río Uruguay. Como indicador de los niveles de rivalidad puede señalarse que los "infieles" coaligados que pretendían atacar los pueblos de misiones del Uruguay consideraban necesario matar los guenoas que había entre ellos "para que no den aviso a sus parientes convertidos". ${ }^{40}$ El desconocimiento de los detalles del conflicto, y por ende del lugar de procedencia - entre los ríos Paraná y Uruguay - de los charrúas, contribuyó al equívoco sobre el radio de acción ya señalado. ${ }^{41}$ Las razones que esgrimieron los jesuitas para aceptar el concurso guenoaminuán fueron igualmente elocuentes en el sentido de precisar la riva-

37 El gobernador de Buenos Aires al Rey. Buenos Aires, 28 de abril de 1690: ibidem.

38 "Estas naciones de indios charrúas, y guinoanes, se mantienen de algunos años a esta parte, a devoción de este gobierno, y como sus distritos están de la otra banda del río Paraná, son dueños de las dilatadas campañas, muchos caballos, innumerables tropas de ganado vacuno que confinan con Colonia del Sacramento, y pudiera suceder [que los portugueses] los llegasen a conseguir". El gobernador de Buenos Aires al Rey. Buenos Aires, 28 de abril de 1690: ibidem.

${ }^{39}$ Declaración de Gabriel de Toledo, en expediente sobre faenas portuguesas en la campaña, 2 de abril de 1693: AGI, Charcas, 262.

${ }^{40}$ Papel presentado por el provincial de la Compañía de Jesús, padre Ignacio de Trías al gobernador de Buenos Aires, remitido por el padre superior de Misiones. Declaración adjunta: AGNA, IX-41-1-3. Exp. 1, fs. 148-149.

${ }^{41}$ Diego Bracco, Una Degollación de Charrúas (Montevideo 1999). 
lidad existente y los respectivos territorios donde cada "nación" era preponderante. Así, cuando el ejército guaraní, encabezado por cinco cabos españoles y varios padres de la Compañía, se dirigía a las campañas orientales del río Uruguay,

"[...] llegó aviso de los Indios Guenoas amigos pidiendo socorro y prometiendo ayudar contra el Yaro ${ }^{42}$ su enemigo, y nuestro. Consultando también nos pareció que por mandar el Sr. Gobernador el amparo de los Indios amigos, y por ser de grande importancia el tener al Guenoa de nuestra parte por ser expertos en la guerra de los Yaros, se le debía dar socorro y valerse de él, principalmente yendo el ejército a donde estaban los dichos guenoas". ${ }^{4}$

Tal predominio guenoa explica las razones que obligaban a los jesuitas a llevar abundante tributo en yerba, tabaco y ponchos durante la recogida anual de vacas realizada en el interior del territorio. ${ }^{44} \mathrm{~A}$ partir del año 1705 hubo un cambio en los sistemas de alianza, probablemente como consecuencia de la expulsión de los portugueses de la Colonia. Lo que antes había sido alianza de jesuitas y guenoas contra “infieles" occidentales del Uruguay pareció transformarse en una confederación de nómadas contra la sociedad jesuítico-guaraní. Los jesuitas anunciaban en 1707 que se estaban

"[...] previniendo para el castigo de los infieles guanoas, bojanes y charrúas confederados, por haber hecho muchas hostilidades en los indios guaraníes, robando, apresando y matando muchos de dichos guaraníes, acometiéndolos a traición de noche, habiendo tratado antes con ellos como con amigos". ${ }^{45}$

Los guenoas tuvieron en el nuevo contexto la suficiente fortaleza militar para impedir la continuación de las arreadas de ganado destinado a los pueblos de misiones, generando hambre. Condolido "el apostólico

42 Yaro habría sido la parcialidad charrúa que confinaba con Yapeyú. Según el padre Sepp, yaro era el modo en que localmente se denominaba a los "infieles". Véase la carta de Antonio Sepp en Cartas edificantes y curiosas escritas de las missiones estrangeras y de levante por Algunos Misioneros de la Compañía de Jesús, tomo VII (Madrid 1753), pp. 383-384.

${ }^{43}$ Consejo de guerra "sobre este río Ibicuí, estancia del pueblo de San Borja". 25 de diciembre de 1701: AGNA, IX-41-1-3. Exp. 1, fs. 325-328.

${ }^{44}$ El ingeniero Campal estimó en 350 las mulas que transportaban tal carga - en parte destinada a los propios vaqueros - durante la recogida de ganado del año 1705 . José Cardiel/Silvestre González, Las Vaquerías del Mar (Montevideo 1968), introducción, notas y mapas del Ing. Esteban Campal.

45 Copia de un escrito trunco y sin fecha del padre Bartolomé Ximénez (año 1707): AGNA, IX-7-9-1. 
misionero y venerable mártir padre José de Arce [fue a sus tierras] poniendo tanta gracia en sus labios que redujo a los guenoas y sus aliados a la paz" gracias a lo cual la guerra habría cesado en $1710 .{ }^{46} \mathrm{En}$ 1715 , en filas del contingente militar guaraní misionero que se desplazó hacia el territorio situado entre los ríos Paraná y Uruguay al castigo de los charrúas, prestaron servicio "guenoas cristianos" y "guenoas infieles". 47

Entretanto, desde Buenos Aires se temían las actividades extranjeras en la ribera norte del estuario. Y "porque se tiene entendido que por aquellas campañas andan vaqueando cantidad de indios, de nación guaynoas" se expedían órdenes para procurar evitar que cooperaran con el enemigo. ${ }^{48}$ Tal ocurrió así consistentemente debido a que

“[...] la Nación de más fuerza que domina dichas campañas es la de los Binuanes, los cuales asisten de ordinario por el verano en las cercanías de las Sierras de Maldonado, y por el invierno se retiran a la parte del río Negro, que desagua en el Uruguay". ${ }^{49}$

Aunque rara vez mantuvieron enfrentamiento frontal con los españoles, los guenoas-minuanes tendieron a prestar sus servicios de acuerdo a conveniencias ocasionales y así también

"[...] los portugueses que habitan en la Colonia del Sacramento han hecho y hacen faenas de corambres de toros, ayudados de los indios infieles nombrados los minuanes, y otras naciones, quienes teniendo como han tenido siempre su habitación en Castillos que está bastantemente distante de la población de dichos portugueses, se han venido a ella, o bien sea con las dádivas y agasajos que les hacen estos, con los cuales se muestran los referidos indios muy amigos, de donde resulta que estos, junto con algunos peones que se han pasado de esta Ciudad a dicha Colonia, hacen las faenas de corambres en Montevideo y otros parajes". ${ }^{50}$

Sin perjuicio de tales acusaciones, desde Buenos Aires se les halagaba con presentes que ocasionalmente arrojan luz sobre la intensidad del

\footnotetext{
${ }^{46}$ Lozano, Historia (nota 2), tomo III, p. 466. Conviene advertir que la obra de Lozano habría sido finalizada en 1745, permaneciendo inédita hasta 1873.

47 "Informe del padre Policarpo Dufo, sobre lo sucedido en la entrada que hizo el año de 1715 al castigo de los infieles": Revista del Archivo General de Buenos Aires II (Buenos Aires 1870), pp. 245-261.

48 Auto del gobernador Herrera. Buenos Aires, 8 de noviembre de 1683 . Instrucciones ante aviso de presencia de un navío francés: AGNA, Tribunales, 288. Exp. 16.

${ }^{49}$ Copia de memorial conteniendo propuesta de José García Inclán, sobre poblar en Montevideo, remitido al Consejo en 8 de noviembre de 1720: AGI, Charcas, 237.

${ }^{50}$ Los Oficiales Reales al Rey, Buenos Aires, 10 de septiembre de 1721: AGI, Charcas, 226.
} 
proceso de aculturación..$^{51}$ Tal era el contexto cuando, por reacción a la presencia lusitana, los españoles principiaron a establecerse en Montevideo, donde "a la vista de este nuevo lugar, en sus campos, y ríos, hay más de dos mil indios infieles llamados minuanes". ${ }^{52}$ La expansión de la sociedad colonial española y el subsiguiente conflicto por los recursos de la campaña desembocaron en un gran alzamiento guenoa-minuán, contenido por mediación de la Compañía de Jesús. El camino hacia la paz entre Montevideo y esos "infieles" no estuvo exento de dificultades.$^{53}$ Los guenoas-minuanes parecen haber negociado desde una situación de fuerza ya que, por ejemplo, no accedieron a devolver los caballos "cogidos en buena guerra". ${ }^{54}$

51 Por orden del gobernador de Buenos Aires, en diciembre de 1721, el capitán Pando y Patiño pasó a ver a los indios minuanes. En esa ocasión les llevó de presente "1 docena y $1 / 2$ de barajas". Cuenta de lo gastado por orden del gobernador, por el capitán Pando y Patiño [...] cuando por el mes de diciembre de 1721 pasó a ver los indios minuanes: AGI, Contaduría, 1937. 153.

52 Fray Jerónimo de la Cruz al Rey, Montevideo, 29 de agosto de 1724: AGI, Chile,

${ }^{53}$ El 27 de febrero de 1732 el cabildo de Montevideo recibió a los enviados del gobernador de Buenos Aires, que llegaron "por diputados para celebrar y ajustar la paz entre los indios minuanes quienes han infestado estas campañas con robos y muertes y habiendo sus mercedes llegado a esta Ciudad [...] aún antes que desembarcasen, llegaron [...] diecinueve minuanes y entre ellos un cacique que dijo llamarse Tacú, [...] y ese mismo día se tuvo la primera conferencia, dándose los demás pasos que este ilustre cabildo no ignora, de que resultó haber dichos indios y cacique ofrecido ir por los demás caciques para con ellos ajustar la dicha paz[...] y faltando a todo lo capitulado mandaron volver [a cuatro españoles que se había pactado que los acompañaran] dichos españoles y que no fuesen a los toldos". Acta de la sesión del Cabildo de Montevideo de 27 de febrero de 1732: AGN, Fondo ex Archivo General Administrativo, libro 6, año 1732, folio 59 v. Publicado en Comisión Nacional Archivo Artigas, Archivo Artigas, tomo I (Montevideo 1950), pp. 68-69.

${ }^{54}$ El 22 de marzo de 1732 a Montevideo "concurrieron dos caciques minuanes con treinta indios y entre los dichos un capitán, y se llaman Don Agustín, Guitabuiabo y el capitán Francisco [...] con quienes se trató y ajustó la paz, por decir estos que traían para ello facultad de los demás caciques [...] y habiéndoles dado a entender los siete capítulos contenidos en la instrucción de su Excelencia, consintieron en todo menos en el capítulo sexto, que respondieron estar los caballos repartidos en diferentes partes y haberse disipado muchos de ellos en el remedio de sus necesidades, además de ser cogidos en buena guerra [...] lo cual ofrecieron dichos caciques y capitán por sí, y en nombre de todos los demás caciques, como que traían de ellos la facultad y que estos no pudieron bajar por quedar en guarda de sus toldos, con la noticia que han tenido de bajar un trozo de indios tapes sin saber el motivo que dichos tapes tienen para bajar armados a sus tierras". Paz de los Indios Minuanos, Montevideo, 22 de marzo de 1732: AGNA, IX-20-8-6. Publicado en Archivo Artigas (nota 53), tomo I, p. 70. 
La carta del misionero Miguel Ximenez, destacado como mediador ante los indígenas, es una magnífica instantánea de lo que ocurría en el interior del territorio y de esa "nación". En ella volvió a quedar en evidencia que el espacio sobre el que ejercía su influencia el cacique de caciques de los guenoas-minuanes era superior al de la actual República Oriental del Uruguay. ${ }^{55}$

Las fuentes portuguesas también señalan las dimensiones y algunos aspectos de la profundidad temporal del dominio sobre tal espacio, con considerable antelación al establecimiento en Río Grande. Así, en 1715, desde Laguna, se había mandado

“[...] trinta pessoas até o Rio Grande, jornada daí de pouco menos de um mês [...] e levaram orden os da dita tropa de fazerem povoaçäo no distrito do Río Grande e procurarem facilitar o trato com o Gentío Minuano, que anda à vista, vago, na campanha, de que se espera amizade e conservaçäo, e ainda a sua conversäo de que resultará grande e considerable utilidade [...] [asegurando el pasaje] do Río Grande" ${ }^{56}$

Luego de las fundaciones de Montevideo y Río Grande, la presión española y portuguesa hacia el interior del territorio se intensificó. ${ }^{57}$ Ello no ocurrió de modo uniforme, y hubo sensibles variaciones a causa de los avatares de la política europea. La más notable consecuencia de esos avatares fue la denominada guerra guaranítica. ${ }^{58}$ Poco antes de mediados de siglo XVIII, las necesidades militares españolas frente a los "infieles" del occidente del Paraná disminuyeron. Tal circunstancia fue muy influyente al liberar recursos militares de Buenos Aires y Santa Fe que pasaron a ser usados contra los indígenas situados al oriente de ese río.

55 Carta del Padre Miguel Ximénez, de 10 de agosto de 1731, transcripta por el padre Pedro Lozano al padre procurador general Sebastián de San Martín, Córdoba de Tucumán, 30 de enero de 1732: Biblioteca Nacional de Madrid, Ms., no. 12.97734.

56 Provisâo do Conselho Ultramarino, Livro primeiro do registro da Cámara da Vila da Laguna, p. 35, publicado en Feliciano Fernandes Pinheiro, Anais da Provincia de Säo Pedro (Petrópolis/Rio de Janeiro/Brasilia 1978), p. 197.

57 Además, la presión de un nuevo actor social - el que más adelante sería denominado gaucho - fue muy relevante.

58 Es interesante el papel desempeñado por los guenoas-minuanes que devinieron comandantes de las huestes guaraníes privadas del concurso de los padres de la Compañía. Carta del padre Tadeo Henis al padre Bernardo Nusdorffer en respuesta al pedido de informes del segundo, hasta el presente día 4 de marzo de 1756: Anais da Biblioteca Nacional do Rio de Janeiro LIII (Río de Janeiro 1938), pp. 393-395. 
En 1743 se señaló que en el camino entre Yapeyú y Santa Fe no se habían visto charrúas "porque todos se han pasado a la otra banda de Uruguay y tienen esperanza de refugiarse en este pueblo [Yapeyú]". ${ }^{59}$ En esa década, Yapeyú y San Borja - respectivamente al occidente y oriente del río Uruguay - recibían cierto flujo de "infieles" charrúas y guenoas. ${ }^{60}$ Dicho flujo continuó evidenciando la importancia del mencionado río como divisoria entre los radios de acción de las "naciones" nómadas. Inmediatamente antes que se produjeran los grandes cambios derivados de la campaña militar de los años 1749-1750, el gobernador de Buenos Aires informaba que "desde el Campo del Bloqueo de la Colonia del Sacramento hasta el Río Grande que están situados los portugueses, habitan los indios infieles minuanes". ${ }^{61} \mathrm{El}$ expresado gobernador indicó asimismo que "desde el Campo del Bloqueo hasta la ciudad de las Corrientes, por una y otra parte del río Uruguay, y pueblos de Misiones de los guaraníes, habitan los indios charrúas, manchados, martianes, bojanes, y yaros". ${ }^{62}$

También señaló el propósito de procurar la total destrucción de los "infieles" mediante una operación militar, ${ }^{63}$ de la que derivaron muy relevantes modificaciones en la ocupación del espacio. ${ }^{64}$ Así, entre la primavera de 1749 y el verano siguiente, la combinación de esfuerzos coloniales ${ }^{65}$ consiguió una victoria que tuvo las siguientes consecuencias: una cantidad apreciable de charrúas buscó amparo en el pueblo

${ }^{59}$ Carta del padre José Ribas al padre Antonio Machoni, Yapeyú, 30 de abril de 1743: AGNA, IX-6-9-7.

${ }^{60}$ Informe al Rey del provincial de la Compañía de Jesús, Bernardo Nusdorffer, Buenos Aires, 30 de agosto de 1745: AGI, Buenos Aires, 384.

${ }^{61}$ Informe del gobernador Andonaegui al marqués de la Ensenada, Buenos Aires, 5 de setiembre de 1749: AGI, Buenos Aires, 304.

62 Ibidem.

63 Ibidem.

64 "El vacío de los indios infieles lo ocuparon en parte un no corto número de hombres viciosos, que huyendo por sus excesos de las ciudades de esta provincia [Buenos Aires] y sus confinantes del Tucumán y Paraguay, buscaban su refugio en los espesos montes y bosques de que abundan estos parajes". Representación a su Majestad, año 1805: Oscar F. Urquiza Almandoz, "La Fundación de las Primeras Villas Entrerrianas y la Representación a Carlos IV": Academia Nacional de Historia, VI Congreso Internacional de Historia de América, tomo III (Buenos Aires 1982), p. 246.

65 Andonaegui al virrey del Perú, Buenos Aires, 20 de julio de 1750: AGI, Charcas, 199. El gobernador de Buenos Aires dio orden para que se entrara a sus tolderías simultáneamente, desde cuatro sitios, con los cuales, fuera de los que se pasaron a cuchillo, fueron capturadas hasta 90 familias. 
misionero de Yapeyú ${ }^{66}$ o fue enviado allí a la fuerza. ${ }^{67}$ Un número difícil de cuantificar murió durante la operación ${ }^{68}$ y una cifra también difícil de estimar pasó a los campos menos controlados del oriente del río Uruguay. ${ }^{69}$ Por último, un contingente cercano a los 400 individuos se avino a la vida en reducción denominada Purísima Concepción de Cayastá, en las cercanías de Santa Fe. ${ }^{70}$ Sucesivos pagos a los franciscanos $^{71}$ que allí asistían permiten establecer que la población se mantuvo relativamente estable. ${ }^{72}$ Después de estos acontecimientos, la presencia "infiel” entre los ríos Paraná y Uruguay fue escasa. ${ }^{73}$ Los que consiguieron escapar de la muerte y de la reducción ${ }^{74}$ pasaron a engrosar las filas de los que ya operaban al oriente del Uruguay. ${ }^{75}$ La abundante documentación de la segunda mitad del siglo XVIII los muestra actuando en ese escenario con muy importantes consecuencias historiográficas.

La migración de los charrúas sobrevivientes comprimió el territorio que hasta la década de 1740 fue guenoa. En 1743 un tercio de los indios que formaban el pueblo de San Borja eran guenoas, a quienes visitaban sus parientes del

\footnotetext{
${ }^{66}$ Borrador aparentemente del gobernador Andonaegui, al parecer destinado al comandante del Campo del Bloqueo, 12 de octubre de 1750. Informa sobre noticias recibidas del procurador de Misiones, sobre afluencia charrúa, temerosa por los recientes sucesos militares, que se han agregado, o se dirigen a hacerlo a Misiones: AGNA, IX-23-3-4.

${ }^{67}$ Desde Santo Domingo se remitieron "seis piezas de las que se cogieron a los charrúas" a Yapeyú, en circunstancias en que el camino por tierra a ese pueblo de misiones estaba interrumpido por la amenaza "infiel", "pues si antes eran solos los charrúas y sus parciales, ahora se les han agregado los minuanes, que son los de mayor número". Carta de José de San Román al gobernador de Buenos Aires, Santo Domingo, 16 de enero de 1750: AGNA, IX-4-3-1.

68 Auto del gobernador de Buenos Aires, Santa Fe, 11 de abril de 1750: AGNA, Manuscritos de la Biblioteca Nacional. Ms. (en adelante BN Ms.), 5594.

${ }^{69}$ La noticia del éxito militar colonial fue recibida y divulgada con satisfacción al oriente del río Uruguay. Bruno Mauricio Zabala al gobernador de Buenos Aires, Víboras, 24 de marzo de 1751: AGNA, IX-23-3-4.

${ }^{70}$ Acta de posesión, en el paraje del arroyo de Cayastá, jurisdicción de Santa Fe, 17 de septiembre de 1750: AGNA, BN Ms., 5594.

${ }^{71}$ Informe de fray Pedro José de Parras, 9 de abril de 1751: AGI, Charcas, 378.

72 AGI, Contaduría, 1886a; 1889; 1890.

73 Vera Mujica al padre Nusdorffer, 14 de marzo de 1751: AGNA, IX-7-9-4.

74 Vera Mujica al padre Nusdorffer, 25 de mayo de 1751: ibidem.

75 Reclamo de Rosa de Illescas, mujer del corregidor de Santo Domingo; recibo de 2 de enero de 1750, y orden de pago de 5 de enero de 1752: AGI, Contaduría, 1886 b.
} 
“[...] tramo de tierra y campaña que median entre el río Negro, Montevideo, y el Río Grande, hasta términos del Brasil [dónde] habitan varias parcialidades de indios infieles guenoas (o como llaman en Buenos Aires, minoanes)" ${ }^{76}$

Para intentar convertirlos, salvando los obstáculos relacionados con las grandes distancias, ${ }^{77}$ se estimó conveniente establecer residencia de la Compañía de Jesús en Montevideo "que fuese como escala para esta Misión". ${ }^{78}$

Durante la segunda mitad del siglo XVIII, los guenoas-minuanes continuaron siendo

"[...] los indios dominantes de la otra banda del Uruguay; aunque el gobernador de Montevideo, Viana, [en la década de 1750] les dio un golpe cruel, con todo permanecen todavía bastantes, cuya principal habitación es de la costa de los Saltos adentro, y es riesgo en que andan los beneficiadores del campo. Se extienden también a los pueblos de San Miguel, y Yapeyú, tratando pacíficamente con ellos, aunque alguna vez acontecen sus lances [...] Andan entre ellos indios misioneros, españoles, y portugueses vagos". ${ }^{79}$

Los guenoas-minuanes unieron ocasionalmente sus fuerzas a los charrúas que habían escapado de la muerte y de la reducción en la campaña de 1749-1750. Como respuesta al acoso recibido desde diversos frentes, especialmente por partidas de gauchos, "formaron un cuerpo y plantaron sus tolderías" a doce leguas de las estancias fronterizas del río Negro. Ante la cercanía "infiel” hubo acción militar colonial, consecuente reacción ${ }^{80}$ y una nueva expedición colonial, ${ }^{81}$ que los derrotó en varios sitios, tomando en uno de ellos 164 prisioneros. ${ }^{82} \mathrm{El}$ coman-

${ }^{76}$ Petición del procurador de la Compañía de Jesús, padre Juan José Rico, sin fecha, pero visto en Consejo en 17 de octubre de 1743: AGI, Charcas, 384.

77 Oficio del gobernador de Buenos Aires al Rey, 9 de septiembre de 1745: AGNA, BN Ms., 1188. Se precisó con frecuencia el enorme radio de acción de los guenoas. Así, en 1745 el gobernador de Buenos Aires, en obediencia a real cédula de 9 de diciembre de 1743 se disponía a cooperar con los jesuitas que desde Montevideo debían ir "a los parajes que median entre el río Negro, Montevideo y el Río Grande hasta los términos del Brasil, a reducir a poblaciones a los indios minoanes que se mantienen en su infidelidad que les ocasiona el andar bagamundos por aquellos campos en rancherías portátiles".

78 Real Cédula, Buen Retiro, 31 de diciembre de 1744: AGNA, BN Ms., 1182.

79 Real Academia de la Historia, Papeles de Juan Francisco Aguirre, Fondo General, Est. 21 - Gr. 5-No. 93.

${ }^{80}$ Félix de Azara a Olaguer Feliú, Cerro Largo, 11 de febrero de 1798: AGNA, IX$1-3-5$.

81 Acosta y Lara, La guerra (nota 5), cap. XI.

82 Oficio del comandante de Colonia A. de Pinedo al virrey, Colonia, 23 de agosto de 1798: AGNA, Colonia del Sacramento, legajo 8. 
dante a cargo estimaba factible exterminarlos o reducirlos con una partida estable en el rincón del Arerunguá, o Arapey. Señaló la "cortedad de la nación charrúa" y que la "nación" minuana era de mayor consideración, pero regularmente estaba más lejos, entre el río Ibicuí, y la sierra de Santa María. ${ }^{83}$ En 1804 el mismo oficial señaló que se podía contener a los "infieles" con un destacamento situado en Arerunguá ya que hacia la costa del Uruguay no había

“[...] más que cortas cuadrillas de ladrones asociados de algunos indios y más tapes que charrúas [...] siempre que haya tesón en mandar partidas gruesas en persecución del minuan, que es el cuerpo de indios considerable que hay". ${ }^{84}$

Al parecer todo estaba pronto cuando principiaba el siglo XIX para que los demás actores sociales del espacio de frontera asestaran el golpe final a los grupos que subsistían en la "infidelidad". 85 Para entonces, eran un único problema para la sociedad colonial, lo cual ha contribuido a oscurecer las diferencias que hubo entre ellos. Con relación a tales, conviene señalar que en 1793 se invitó a caciques charrúas y minuanes para que visitaran Candelaria y otros pueblos. Las autoridades coloniales se proponían de ese modo persuadirlos para que pasaran a vivir allí con su gente. ${ }^{86}$ Entre otras diferencias, todavía entonces se consideró necesaria la presencia de "uno o dos lenguaraces en las lenguas charrúa y minuana" junto a los caciques. ${ }^{87}$

\footnotetext{
${ }^{83}$ Francisco Albín al virrey Avilés, en respuesta a pedido de informes, San Salvador, 24 de septiembre de 1799: AGNA IX-23-3-6.

${ }^{84}$ Oficio de Francisco Albín al virrey Sobremonte, San Salvador, 27 de junio de 1804: AGNA, IX-3-8-5. El informe fue en respuesta a solicitud del virrey, inquiriendo sobre conveniencia de abandonar Arerunguá y a cambio destacar 100 hombres en Tacuarembó y otros 100 en Belén.

85 "Nueve son las tolderías que existen, de las cuales siete se encuentran conmigo aquí, y las dos restantes están en la guardia portuguesa del Ñanduy, incidente que me ha retraído la evacuación de todo mi plan, porque tengo esperanzas de arrancarlos de allí, y después de reunidos, darles el golpe sin efusión de sangre, trasladándolos con sus familias a esa Ciudad, para que Vuestra Señoría los distribuya por esa frontera, el Reino de arriba, o les de el destino que le parezca conveniente". Oficio de Jorge Pacheco al virrey, Belen, 29 de julio de 1807: AGNA, IX-20-1-7. Es interesante señalar alguna similitud con el plan que terminó con la presencia "infiel” en la naciente República Oriental del Uruguay, tres décadas más tarde.

${ }^{86}$ Hoja - padrón, en guaraní, anexa a carta de Juan Antonio Sancho a Francisco Bruno de Zabala, Yapeyú, 28 de marzo de 1794: AGNA, Tribunales, legajo 66, exp. 38.

${ }^{87}$ Francisco Bruno de Zabala al virrey Arredondo, Candelaria, 24 de marzo de 1794: AGNA, Tribunales, legajo 66, exp. 38.
} 
La inestabilidad relacionada con la crisis del sistema colonial en la región difirió el fin de las "naciones" indígenas hasta la década de 1830. Los abordajes historiográficos de carácter nacionalista y/ o con marcado énfasis en los aspectos éticos de la cuestión han conferido una importancia extraordinaria a ese período. Sin perjuicio de ello, la documentación evidencia que al inicio de las guerras de la independencia el camino hacia la destrucción de las "naciones" indígenas era un proceso irreversible. Sin pretender que haya sido lineal, tal proceso comenzó con la llegada de los europeos, aunque conviene reiterar que poco puede afirmarse sobre el vasto interior hasta que se produjo la difusión de vacunos y equinos. No obstante, es necesario insistir en que las fuentes no autorizan a señalar la preponderancia charrúa. En cambio, desde que se produjo documentación que describe el interior, fue señalada la preponderancia de la "nación" guenoa-minuana entre el río Uruguay, los pueblos australes de misiones y el oeste de la cuenca de la Laguna de los Patos. Tal preponderancia continuó existiendo, pero fue compartida a partir de 1750 , cuando los charrúas fueron forzados a abandonar su territorio tradicional. Esta circunstancia contribuyó considerablemente para que la sociedad colonial percibiera a las "naciones" indígenas como un único problema, y ello tuvo relevantes efectos historiográficos. De cualquier modo, la documentación continuó evidenciando diferencias entre guenoas-minuanes y charrúas. Esas diferencias condicionaron durante un largo período las tendencias a las alianzas que fueron muy relevantes en el proceso histórico regional. 